Article

\title{
Optimization of Ultrasound-Assisted Extraction of Natural Antioxidants from Sugar Apple (Annona squamosa L.) Peel Using Response Surface Methodology
}

\author{
Gui-Fang Deng ${ }^{1, *}$, Dong-Ping $\mathrm{Xu}^{2}$, Sha $\mathrm{Li}^{2}$ and Hua-Bin $\mathrm{Li}^{2}{ }^{2} *$ \\ Received: 30 September 2015 ; Accepted: 9 November 2015 ; Published: 17 November 2015 \\ Academic Editor: Derek J. McPhee \\ 1 Department of Clinical Nutrition, Nanshan Hospital, Shenzhen 518052, China \\ 2 Guangdong Provincial Key Laboratory of Food, Nutrition and Health, School of Public Health, \\ Sun Yat-Sen University, Guangzhou 510080, China; xudongping1989@163.com (D.-P.X.); \\ lishas10308@163.com (S.L.) \\ * Correspondence: misyfly@163.com (G.-F.D.); lihuabin@mail.sysu.edu.cn (H.-B.L.); \\ Tel.: +86-755-265-531-11 (G.-F.D.); +86-20-873-323-91 (H.-B.L.)
}

\begin{abstract}
Sugar apple (Annona squamosa L.) is a popular tropical fruit and its peel is a municipal waste. An ultrasound-assisted extraction method was developed for the recovery of natural antioxidants from sugar apple peel. Central composite design was used to optimize solvent concentration $(13.2 \%-46.8 \%)$, ultrasonic time $(33.2-66.8 \mathrm{~min})$, and temperature $\left(43.2-76.8^{\circ} \mathrm{C}\right)$ for the recovery of natural antioxidants from sugar apple peel. The second-order polynomial models demonstrated a good fit of the quadratic models with the experimental results in respect to total phenolic content (TPC, $\left.R^{2}=0.9524, p<0.0001\right)$, FRAP $\left(R^{2}=0.9743, p<0.0001\right)$, and TEAC $\left(R^{2}=0.9610, p<0.0001\right)$ values. The optimal extraction conditions were $20: 1(\mathrm{~mL} / \mathrm{g})$ of solvent-to-solid ratio, $32.68 \%$ acetone, and $67.23{ }^{\circ} \mathrm{C}$ for $42.54 \mathrm{~min}$ under ultrasonic irradiation. Under these conditions, the maximal yield of total phenolic content was 26.81 (mg GA/g FW). The experimental results obtained under optimal conditions agreed well with the predicted results. The application of ultrasound markedly decreased extraction time and improved the extraction efficiency, compared with the conventional methods.
\end{abstract}

Keywords: sugar apple peel; antioxidant; ultrasound-assisted extraction; response surface methodology

\section{Introduction}

Fruit wastes are one of the main sources of municipal wastes. Due to the high consumption and industrial processing of fruit edible parts, fruits residues (principal peels and seeds) are generated in large quantities in large cities and become a severe environmental issue. However, if the phytochemicals of fruit residues were extracted effectively by applying efficient extraction technologies, their value could be added [1,2]. Recently, the contents of natural antioxidants were found to be very high in the peel and seed of some fruits [3-6]. Therefore, it would be beneficial if the fruit residues could be used to recover natural antioxidants especially phenolic compounds, making them fully used in the food, pharmaceutical, as well as cosmetics industry [7].

Annona squamosal L. (Annonaceae) is an important plant and widely distributed in tropical America and Asia [8]. It has long been used as a folk medicine for the treatment of epilepsy, dys entry, cardiac problem, worm infection, constipation, hemorrhage, bacterial infection, dysuria, fever, and ulcers [9]. Annona squamosal bears edible fruits called sugar apple. It is a popular tropical fruit, 
typically globular or heart-shaped, $5-10 \mathrm{~cm}$ in diameter, with many round protuberances. The pulp is sweetly aromatic with a custard-like flavor, and is widely used to prepare juices, jellies, and compotes. The processing of the fruits will leave behind a substantial amount of non-edible parts. In previous studies, extremely high phenolic content and antioxidant capacities were found in sugar apple peel, indicating its potential to be utilized as a resource of natural antioxidants $[4,8]$. So far, there were few studies reporting the optimization extraction of natural antioxidants from sugar apple peel. Recently, ultrasound-assisted extraction (UAE) has been successfully used for the extraction of bioactive compounds from plant matrix [10-13]. It is a simple, efficient, and inexpensive alternative to conventional extraction techniques [14]. Ultrasound has a mechanical effect that enables greater penetration of the solvents into the matrix and increases the surface contact between the solid and the liquid [12]. Ultrasonic cavitation creates shear forces that break cell walls mechanically and enhance mass transfer. Therefore, ultrasound-assisted extraction leads to the improvement of the extraction efficiency $[15,16]$.

The extraction efficiency and antioxidant capacity of natural antioxidants could be markedly influenced by many factors, such as solvent type and concentration, solvent-to-solid, as well as extraction temperature and time [10]. Therefore, it is necessary to optimize the extraction conditions to obtain optimal antioxidant recovery. Response surface methodology (RSM) is an often-used optimization technique that applies sequential experimental techniques to survey a domain of interest, focusing on the most important variables and their effects, as well as the interactions between them, to build an empirical model $[17,18]$. RSM has been successfully used in optimizing the extraction conditions of phenolic compounds from food matrix [10,11,19-22]. Therefore, in the present study, the extraction conditions of natural antioxidants from sugar apple peel was optimized by applying the RSM, employing a three-variable, five-level central composite design, evaluating the influence of solvent concentration, ultrasonic time, and temperature in the process of extraction. The agreement of the experimental results obtained under optimal conditions to the predicted results demonstrated the good suitability of the fitted model. The application of ultrasound markedly decreased extraction time, and improved the extraction efficiency compared with the conventional methods.

\section{Results and Discussion}

\subsection{Preliminary Results}

In the preliminary experiment of our study, the effects of solvent type, solvent-to-solid ratio, acetone concentration, ultrasonic time, and temperature on the extraction of natural antioxidants from sugar apple peel were studied. Under the same extraction conditions $\left(10: 1 \mathrm{~mL} / \mathrm{g}, 25^{\circ} \mathrm{C}\right.$ and $30 \mathrm{~min}$ ), the responses followed a similar trend among all the solvents tested (Figure 1a).

In the literature, several frequently-used solvents were reported, such as ethanol, methanol, and acetone [12,17-21]. In our study, compared to ethanol and methanol, acetone yielded higher responses and was more effective in the extraction of antioxidants from sugar apple peel (Figure 1a). In addition, the extraction efficiency using water was also good. The polarity of the solvent could play an important role in the extraction efficiency [13]. Therefore, the effect of acetone-water at different ratios as extracting solvents was investigated further, and 30\% acetone was optimal (Figure 1b). As for the effect of the solvent-to-solid ratio, six ratios $(5: 1,10: 1,20: 1,30: 1,40: 1,50: 1 \mathrm{~mL} / \mathrm{g})$ were investigated over a $30 \mathrm{~min}$ ultrasonic period, with $30 \%$ acetone, at $25^{\circ} \mathrm{C}$. The results were displayed in Figure 1c. From 10:1 to 20:1, the responses were markedly increased $(p<0.05)$. At the solvent-to-solid ratio of 20:1, a plateau in the mass transfer was reached. There were, indeed, no significant differences for solvent-to-solid ratios between 30:1, 40:1, 50:1, and 20:1 ( $p>0.05)$. In consideration of the solvent consumption and extraction efficiency, solvent-solid ratio of $20: 1(\mathrm{~mL} / \mathrm{g})$ was selected. The effects of extraction temperature and time were shown in Figure $1 \mathrm{~d}$,e, and the optimal values were $60{ }^{\circ} \mathrm{C}$ and $50 \mathrm{~min}$, respectively. According to the results shown in Figure 1b-e, the effects of acetone 
concentration, ultrasonic temperature, and time were more significant on the extract efficiency than solvent-solid ratio; thus, they were further investigated as independent processing variables by RSM.

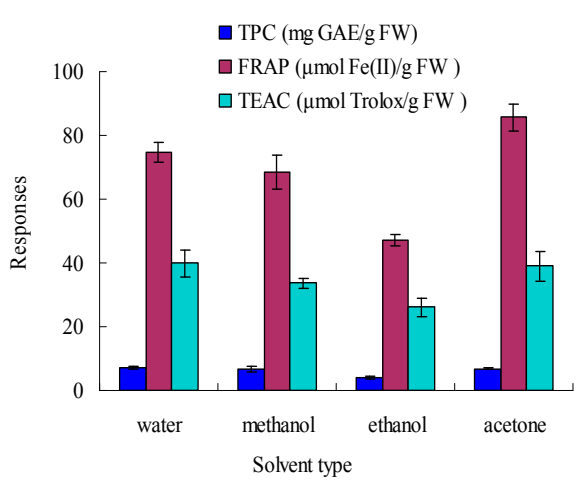

(a)

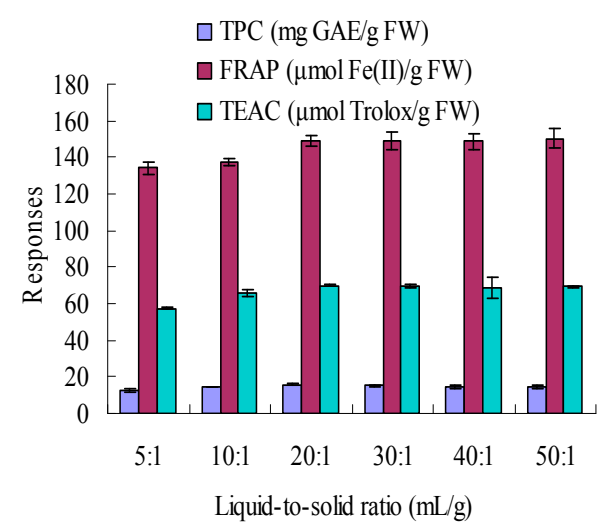

(c)

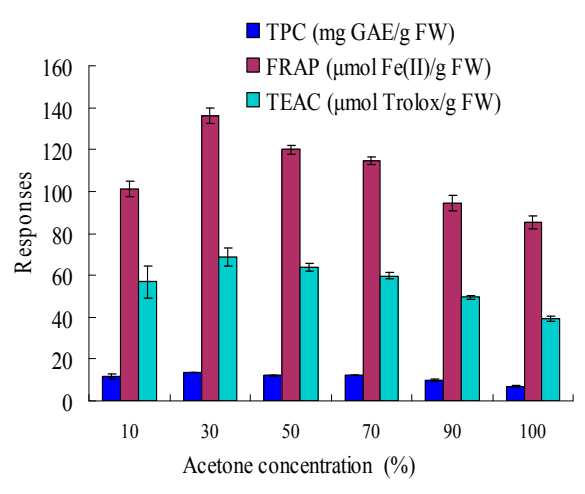

(b)

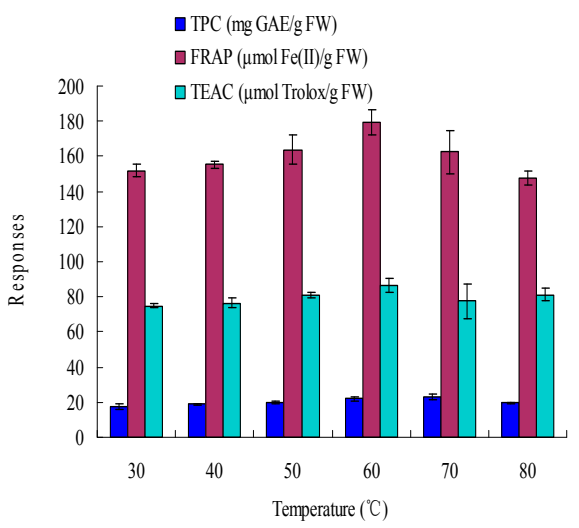

(d)

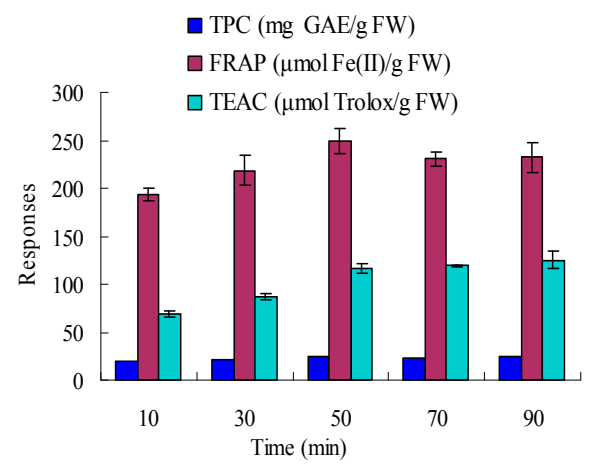

(e)

Figure 1. Effects of solvent type, solvent-to-solid ratio, acetone concentration, ultrasonic time, and temperature on the responses. Extraction conditions: (a) 10:1 mL/g, $25^{\circ} \mathrm{C}, 30 \mathrm{~min}$; (b) 10:1 mL/g, $25{ }^{\circ} \mathrm{C}$ and $30 \mathrm{~min}$; (c) $30 \%$ acetone, $25{ }^{\circ} \mathrm{C}, 30 \mathrm{~min}$; (d) $30 \%$ acetone, $20: 1 \mathrm{~mL} / \mathrm{g}$, $30 \mathrm{~min}$; and (e) $30 \%$ acetone, $20: 1 \mathrm{~mL} / \mathrm{g}, 60^{\circ} \mathrm{C}$.

\subsection{Fitting the Models}

The results of 20 runs using CCD design were shown in Table 1, which included the design and observed responses TPC, FRAP, and TEAC. Total phenolic contents ranged from 15.93 to $26.97 \mathrm{mg}$ GAE/g FW. FRAP and TEAC assays were applied to determine the antioxidant capacities of the extracts. The results showed that FRAP and TEAC values varied from 152.89 to $271.93 \mu \mathrm{mol} \mathrm{Fe}(\mathrm{II}) / \mathrm{g}$ FW, and 72.49 to $124.84 \mu \mathrm{mol}$ Trolox/g FW, respectively. 
Table 1. Central composite design arrangement in terms of the independent variables $\left(X_{1}, X_{2}\right.$, and $\left.X_{3}\right)$ and their observed responses, including Total Phenol Contents (TPC), Ferric-Reducing Antioxidant Power(FRAP), and Trolox Equivalent Antioxidant Capacity (TEAC).

\begin{tabular}{ccccccc}
\hline Run & $\boldsymbol{X}_{\mathbf{1}}$ & $\boldsymbol{X}_{\mathbf{2}}$ & $\boldsymbol{X}_{\mathbf{3}}$ & $\begin{array}{c}\text { TPC (mg } \\
\text { GAE/g FW) }\end{array}$ & $\begin{array}{c}\text { FRAP }(\mu \mathbf{m o l} \\
\text { Fe(II)/g FW) }\end{array}$ & $\begin{array}{c}\text { TEAC }(\mu \mathbf{m o l} \\
\text { Trolox/g FW) }\end{array}$ \\
\hline 1 & $40(1)$ & $60(1)$ & $50(-1)$ & 21.55 & 232.39 & 81.89 \\
2 & $30(0)$ & $50(0)$ & $60(0)$ & 26.24 & 255.54 & 121.03 \\
3 & $20(-1)$ & $40(-1)$ & $50(-1)$ & 22.44 & 180.86 & 73.71 \\
4 & $30(0)$ & $50(0)$ & $76.8(1.68)$ & 26.37 & 259.93 & 100.09 \\
5 & $20(-1)$ & $40(-1)$ & $70(1)$ & 20.72 & 257.57 & 85.88 \\
6 & $30(0)$ & $50(0)$ & $60(0)$ & 24.88 & 252.64 & 115.63 \\
7 & $40(1)$ & $40(-1)$ & $70(1)$ & 23.75 & 258.96 & 113.88 \\
8 & $30(0)$ & $50(0)$ & $60(0)$ & 26.18 & 252.32 & 118.12 \\
9 & $40(1)$ & $40(-1)$ & $50(-1)$ & 19.27 & 200.68 & 93.77 \\
10 & $30(0)$ & $66.8(1.68)$ & $60(0)$ & 26.91 & 252.11 & 97.59 \\
11 & $46.8(1.68)$ & $50(0)$ & $60(0)$ & 15.96 & 207.75 & 102.42 \\
12 & $40(1)$ & $60(1)$ & $70(1)$ & 24.44 & 234.43 & 95.68 \\
13 & $20(-1)$ & $60(1)$ & $70(1)$ & 23.51 & 209.25 & 90.78 \\
14 & $30(0)$ & $50(0)$ & $60(0)$ & 26.94 & 264.86 & 124.86 \\
15 & $30(0)$ & $33.2(-1.68)$ & $60(0)$ & 23.01 & 271.93 & 113.64 \\
16 & $20(-1)$ & $60(1)$ & $50(-1)$ & 24.72 & 179.89 & 93.36 \\
17 & $30(0)$ & $50(0)$ & $60(0)$ & 25.84 & 247.82 & 122.45 \\
18 & $30(0)$ & $50(0)$ & $60(0)$ & 26.97 & 251.07 & 113.72 \\
19 & $13.2(-1.68)$ & $50(0)$ & $60(0)$ & 15.93 & 157.39 & 72.49 \\
20 & $30(0)$ & $50(0)$ & $43.2(-1.68)$ & 21.87 & 152.89 & 77.15 \\
\hline
\end{tabular}

The analysis of variance (ANOVA) of the quadratic regression models for TPC, FRAP, and TEAC showed that the models were significant $(p<0.0001)$ with $F$-values of 22.23, 42.05, and 27.36, respectively (Table 2). The coefficient of determination $\left(R^{2}\right)$ is a measure of degree of fit [23]. For a good fit of a model, $R^{2}$ should be at least 0.80 [24]. In this study, the $R^{2}$ values of the second-order polynomial models for TPC, FRAP, and TEAC were 0.9524, 0.9743, and 0.9610, respectively, which implied that $95.24 \%, 97.43 \%$, and $96.10 \%$ of the variations could be explained by the fitted quadratic models, respectively. Furthermore, the absence of any lack of fit $(p>0.05)$ also strengthened the reliability of all models. The models were used for the construction of three dimensional response surface plots to predict the relationship between the responses and independent variables.

Table 2. Analysis of variance (ANOVA) of the quadratic model and lack of fit.

\begin{tabular}{ccccccc}
\hline Response & Source & Sum of Squares & Mean Squares & DF & F-Test & $p$-Value \\
\hline \multirow{7}{*}{ TPC } & Model & 205.27 & 22.81 & 9 & 22.23 & $<0.0001^{\mathrm{a}}$ \\
& Lack of Fit & 7.25 & 1.45 & 5 & 2.41 & $0.1784^{\mathrm{b}}$ \\
& Residual & 10.26 & 1.03 & 10 & & \\
& Pure Error & 3.01 & 0.6 & 5 & & \\
& $R^{2}$ & 0.9524 & & & & \\
\hline \multirow{5}{*}{ FRAP } & Model & $25,638.96$ & 2848.77 & 9 & 42.05 & $<0.0001^{\mathrm{a}}$ \\
& Lack of Fit & 505.72 & 101.14 & 5 & 2.94 & $0.1305^{\mathrm{b}}$ \\
& Residual & 677.47 & 67.75 & 10 & & \\
& Pure Error & 171.75 & 34.35 & 5 & & \\
& $R^{2}$ & 0.9743 & & & & \\
\hline \multirow{7}{*}{ TEAC } & Model & 5185.6 & 576.18 & 9 & 27.36 & $<0.0001^{\mathrm{a}}$ \\
& Lack of Fit & 120.8 & 24.16 & 5 & 1.34 & $0.3765^{\mathrm{b}}$ \\
& Residual & 210.62 & 21.06 & 10 & & \\
& Pure Error & 89.83 & 17.97 & 5 & & \\
\hline & $R^{2}$ & 0.9610 & & & & \\
\hline
\end{tabular}

Note: a Significant at $5.0 \%(p<0.05) ;{ }^{\mathrm{b}}$ Non-significant. 


\subsection{Effects of Independent Variables on Total Phenolic Contents}

Total phenolic contents of sugar apple peel extracts obtained by ultrasound-assisted extraction were shown in Table 1. The experimental data was subjected to a multiple regression analysis, and the model coefficients were evaluated for significance (Table 3). Regression equation (Equation (1)) showed the relationship between acetone concentration, time, and temperature for the extraction of total phenolic compounds.

$$
\begin{aligned}
& Y_{\mathrm{TPC}}=26.14-0.17 X_{1}+1.07 X_{2}+0.88 X_{3}-0.26 X_{1} X_{2}+1.29 X_{1} X_{3}-0.13 X_{2} X_{3}- \\
& 33.38 X_{1}^{2}-0.19 X_{2}^{2}-0.48 X_{3}^{2}
\end{aligned}
$$

It was evident that the linear effects of time $\left(X_{2}\right)$ and temperature $\left(X_{3}\right)$, and the cross product effect between acetone concentration and temperature $\left(X_{1}, X_{3}\right)$, were positive and significant at $p<0.01$, while the quadratic effect of acetone concentration $\left(X_{1}^{2}\right)$ were negative and significant at $p<0.001$. Figure 2 showed the 3D response surfaces plots of TPC of sugar apple peel extracts. Seen from Figure $2 \mathrm{~b}$, TPC increased with the increase of ultrasonic temperature up to about $67.23^{\circ} \mathrm{C}$, and then began to decline with further rise of temperature. A rise in ultrasonic temperature increased the cavitational intensity, promoting the disruption of the plant tissue and cell wall, and enhancing hydrolysis of the bonds of bound phenolic compounds as well as phenolics solubility $[13,25]$. At higher temperature, solvent viscosity and surface tension were reduced, which could also lead to a better extraction of phenolic compounds [26]. However, some of the thermolabile phenolic compounds might be degraded after the optimum ultrasonic temperature was reached, thereby leading to a decline phenolic content. An extended extraction time favored the extraction of phenolic compounds. However, acetone concentration exerted a quadratic effect on the response; hence TPC gradually mounted up with the increase of acetone concentration, and achieved optimum values at about $32.68 \%$, followed by a decline of TPC with further increase of acetone concentration.

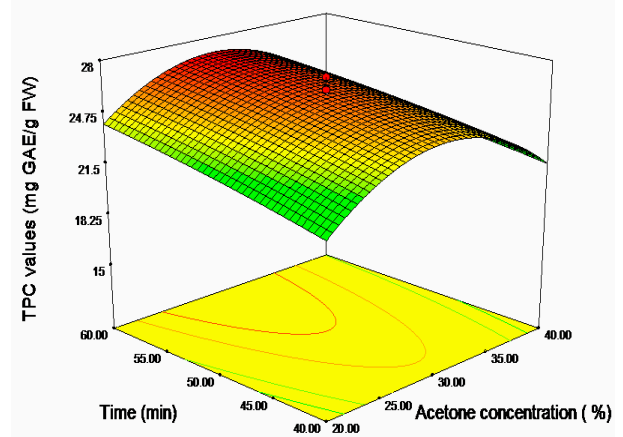

(a)

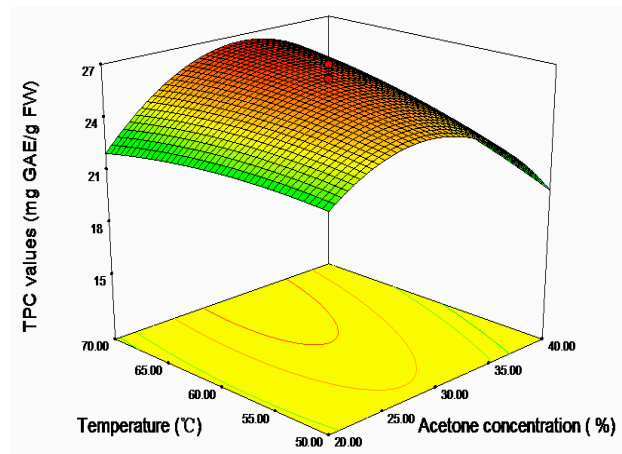

(b)

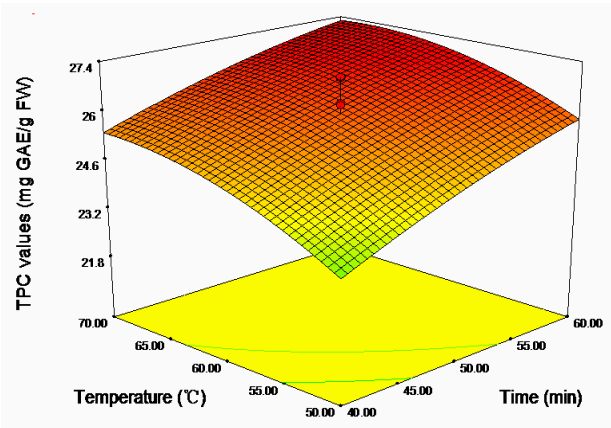

(c)

Figure 2. Response surface plots for the effects of (a) acetone concentration/time; (b) acetone concentration/temperature; and (c) time/temperature on the total phenolic content (TPC). 
Table 3. Estimated coefficients of the fitted second-order polynomial for the investigated responses and their signification based on analysis of variance (ANOVA).

\begin{tabular}{ccccc}
\hline Model Parameter & Coefficient & TPC & FRAP & TEAC \\
\hline $\begin{array}{c}\text { Intercept } \\
\text { Linear }\end{array}$ & $\beta_{0}$ & 26.14 & 253.89 & 119.34 \\
$x_{1}$ & $\beta_{1}$ & $-0.17^{\mathrm{c}}$ & $13.45^{\mathrm{a}}$ & $6.73^{\mathrm{a}}$ \\
$x_{2}$ & $\beta_{2}$ & $1.07^{\mathrm{c}}$ & $-5.53^{\mathrm{b}}$ & -2.38 \\
$x_{3}$ & $\beta_{3}$ & $0.88^{\mathrm{c}}$ & $25.37^{\mathrm{a}}$ & $6.01^{\mathrm{a}}$ \\
Quadratic & & & & \\
$X_{1}^{2}$ & $\beta_{11}$ & $-3.38^{\mathrm{a}}$ & $-24.35^{\mathrm{a}}$ & $-14.91^{\mathrm{a}}$ \\
$X_{2}^{2}$ & $\beta_{22}$ & -0.19 & $3.8^{\mathrm{a}}$ & $-5.1^{\mathrm{c}}$ \\
$X_{3}^{2}$ & $\beta_{33}$ & -0.48 & $-15.91^{\mathrm{a}}$ & $-11.12^{\mathrm{a}}$ \\
Cross product & & & & \\
$X_{1} \times X_{2}$ & $\beta_{12}$ & -0.26 & $7.06^{\mathrm{b}}$ & $-6.83^{\mathrm{c}}$ \\
$X_{1} \times X_{3}$ & $\beta_{13}$ & $1.29^{\mathrm{c}}$ & $-5.72^{\mathrm{a}}$ & 3.04 \\
$X_{2} \times X_{3}$ & $\beta_{23}$ & -0.13 & $-12.95^{\mathrm{c}}$ & -2.63 \\
\hline
\end{tabular}

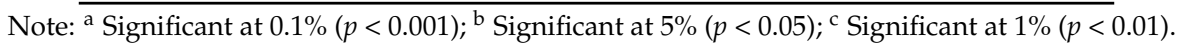

\subsection{Effects of Independent Variables on the Antioxidant Capacities}

The experimental results of antioxidant capacities of sugar apple peel extracts measured by FRAP and TEAC assays were performed regression analysis and the results were shown in Table 3. The relationship of antioxidant capacities between the three independent variables was present in the regression equation (Equations (2) and (3)):

$$
\begin{aligned}
& Y_{\text {FRAP }}=253.89+13.45 X_{1}-5.53 X_{2}+25.37 X_{3}+7.06 X_{1} X_{2}-5.72 X_{1} X_{3}-12.95 X_{2} X_{3}- \\
& 24.35 X_{1}^{2}+3.8 X_{2}^{2}-15.91 X_{3}^{2} \\
& Y_{\text {TEAC }}=119.34+6.73 X_{1}-2.38 X_{2}+6.01 X_{3}-6.83 X_{1} X_{2}+3.04 X_{1} X_{3}-2.63 X_{2} X_{3}- \\
& 14.91 X_{1}^{2}-5.1 X_{2}^{2}-11.12 X_{3}^{2}
\end{aligned}
$$

In term of FRAP, acetone concentration $\left(X_{1}\right)$ and temperature $\left(X_{3}\right)$ showed significantly positive linear effects and negative quadratic effects, respectively $(p<0.001)$. Ultrasonic time showed significantly negative linear effect on the response $(p<0.05)$. The cross product effect between acetone concentration $\left(X_{1}\right)$ and time $\left(X_{2}\right)$ was positive and significant at $p<0.05$, whereas the cross product effect between time $\left(X_{2}\right)$ and temperature $\left(X_{3}\right)$ was negative and significant at $p<0.01$. The 3D response surfaces plot for the effects of independent variables $\left(X_{1}, X_{2}\right.$, and $\left.X_{3}\right)$ on FRAP values were given in Figure 3. As shown, the region of 30\%-35\% acetone concentration, $60-70{ }^{\circ} \mathrm{C}$ and $40-45 \mathrm{~min}$ would achieve a higher FRAC values (maximum $276.47 \mu \mathrm{mol} \mathrm{Fe}(\mathrm{II}) / \mathrm{g}$ FW).

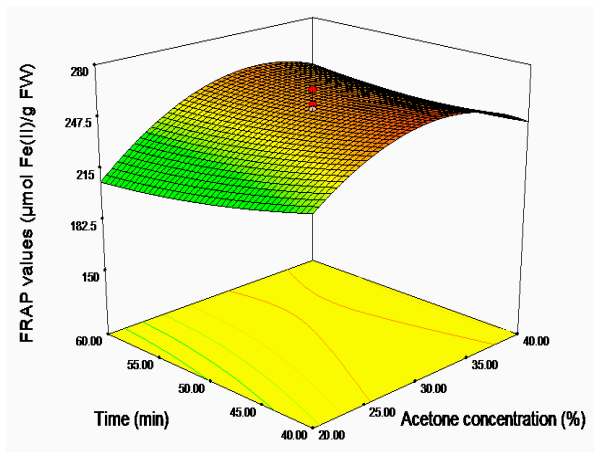

(a)

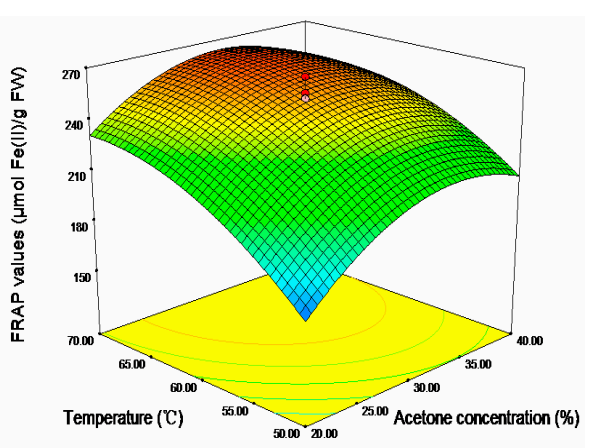

(b)

Figure 3. Cont. 


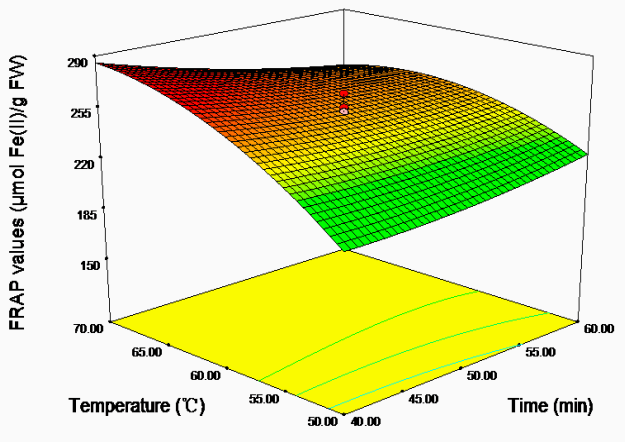

(c)

Figure 3. Response surface plots for the effects of (a) acetone concentration/time; (b) acetone concentration/temperature; and (c) time/temperature on the FRAP values.

In aspect of TEAC, as shown in Table 3, except linear term of time $\left(X_{2}\right)$, cross product terms of time $\left(X_{2}\right)$ and temperature $\left(X_{3}\right)$, all the terms had significant effects on the antioxidant capacities $(p<0.01)$. The $3 \mathrm{D}$ response surfaces plot Figure 4 showed the relationship between the TEAC values and the three independent variables $\left(X_{1}, X_{2}, X_{3}\right)$. Seen from Figure $4 \mathrm{c}$, when the temperature rose from 50 to $65^{\circ} \mathrm{C}$, an apparent increase of TEAC values could be found. However, further increase was limited when the temperature rose from 65 to $70{ }^{\circ} \mathrm{C}$. It was evident that acetone concentration exhibited a similar effect on TEAC values as temperature. An apparent increase of TEAC values was recorded from 20\%-32.68\% (maximum $121.16 \mu \mathrm{mol}$ Trolox/g FW), followed by a moderate decline of TEAC values with further increase of acetone concentration.

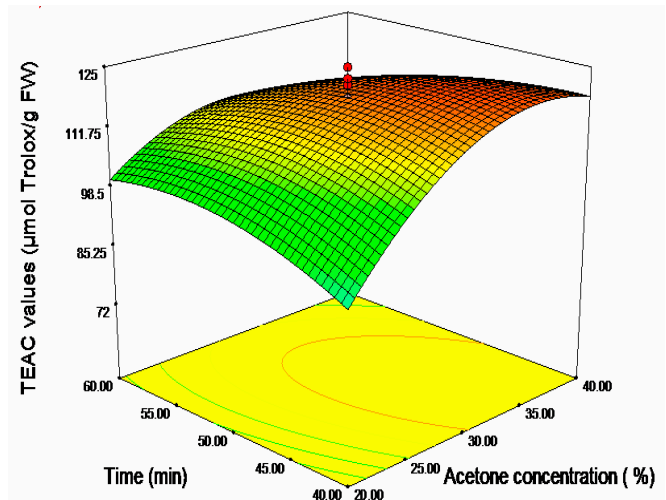

(a)

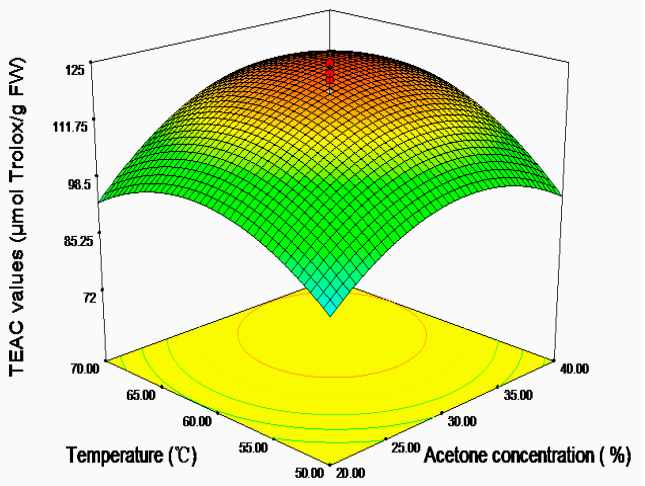

(b)

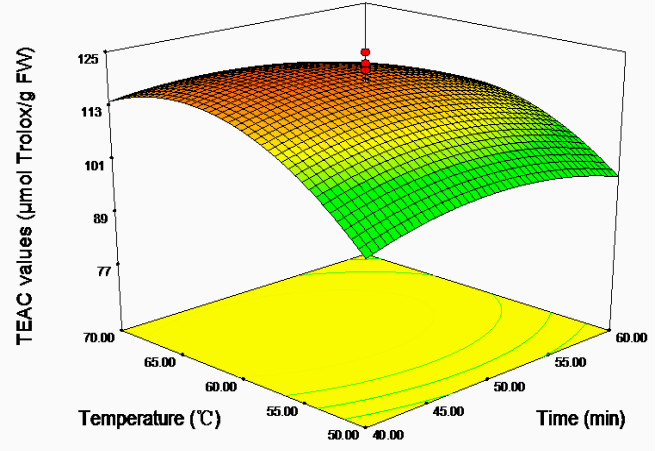

(c)

Figure 4. Response surface plots for the effects of (a) acetone concentration/time; (b) acetone concentration/temperature; and (c) time/temperature on the TEAC values. 


\subsection{Verification of Results}

The optimum extraction conditions obtained by RSM was used to validate the predictive model of extraction for TPC, FRAP, and TEAC values from sugar apple peel. Seen from Table 4, extraction in $32.68 \%$ acetone at $20: 1(\mathrm{~mL} / \mathrm{g}), 67.23{ }^{\circ} \mathrm{C}$ for $42.54 \mathrm{~min}$ under ultrasonic irradiation could result in optimal TPC (26.81 mg GA/g FW), FRAP (280.36 $\mu \mathrm{mol} \mathrm{Fe(II)/g} \mathrm{FW),} \mathrm{and} \mathrm{TEAC} \mathrm{(120.95} \mathrm{\mu mol}$ Trolox/g FW) values from sugar apple peel. The predicted values matched well with the experimental values obtained using optimum extraction conditions, which validated the suitability of the fitted RSM model. Furthermore, compared with conventional methods such as Soxhlet extraction and maceration extraction (Table 4), the application of ultrasonic system for the extraction of antioxidants markedly decreased extraction time, and improved the extraction efficiency, as shown by the $27.7 \%-43 \%$ and $29.7 \%-35 \%$ increase of extraction rate were achieved, respectively.

Table 4. Comparison of experimental results with predicted results obtained by the fitted model and the results obtained by the conventional method.

\begin{tabular}{|c|c|c|c|c|}
\hline \multirow{2}{*}{ Response Variables } & \multicolumn{4}{|c|}{ Extraction Methods } \\
\hline & Predicted & Experimental * & Soxhlet ** & Maceration *** \\
\hline TPC (mg GA/g FW) & 25.70 & 26.81 & 19.59 & 20.67 \\
\hline FRAP $(\mu \mathrm{mol} F e(\mathrm{II}) / \mathrm{g}$ FW $)$ & 276.47 & 280.36 & 196.10 & 211.39 \\
\hline TEAC ( $\mu$ mol Trolox/g FW) & 121.16 & 120.95 & 94.69 & 89.62 \\
\hline
\end{tabular}

\section{Experimental Section}

\subsection{Chemical Reagents and Samples}

The compounds 6-hydroxy-2,5,7,8-tetramethylchromane-2-carboxylic acid (Trolox), 2,4,6-tri(2pyridyl)-S-triazine (TPTZ), 2,2'-azinobis(3-ethylbenothiazoline-6-sulfonic acid) diammonium salt (ABTS), Folin-Ciocalteu's phenol reagent and gallic acid were purchased from Sigma-Aldrich (St. Louis, MO, USA). Acetone, ethanol, methanol, acetic acid, hydrochloric acid, potassium persulphate, iron(III) chloride hexahydrate, iron(II) sulfate heptahydrate, sodium acetate, and sodium carbonate were of analytical grade and obtained from Tianjin Chemical Factory (Tianjin, China). Deionized water was used throughout the experiment.

Sugar apples were collected from markets in Guangzhou, China. Samples were cleaned with deionized water and the peel was separated. Immediately, the separated peel was ground into fine particles with a special grinder.

\subsection{Extraction Procedure}

The ultrasound-assisted extraction process was performed in a ultrasonic device (KQ-600E, $40 \mathrm{kHz}$, Changzhou Nuoji Instrument Company, Changzhou, China) with an electric power of $600 \mathrm{~W}$ (i.e., acoustic power of $0.38 \mathrm{~W} / \mathrm{cm}^{2}$ ), heating power of $800 \mathrm{~W}$, equipped with a digital timer and a temperature controller. In RSM test, sample particles $(0.5 \mathrm{~g})$ were sonicated in the acetone $(10 \mathrm{~mL})$ for different time at set temperature. After sonication, the sample was centrifuged at $9600 \mathrm{~g}$ for $20 \mathrm{~min}$, and then the supernatant was collected and diluted for analysis. The reaction process happened in a $15 \mathrm{~mL}$ centrifuge tube with screw cap and conical bottom, which was fixed in a plastic rack placing in the ultrasonic device.

For comparison, in Soxhlet method, $7.5 \mathrm{~g}$ sample was extracted using $150 \mathrm{~mL}$ of $32.68 \%$ acetone, at $100^{\circ} \mathrm{C}$ for $4 \mathrm{~h}$. In maceration method, $0.5 \mathrm{~g}$ sample was extracted with $10 \mathrm{~mL}$ of $32.68 \%$ acetone in a shaking water bath $(100 \mathrm{rpm})$ at $37^{\circ} \mathrm{C}$ for $24 \mathrm{~h}$. 


\subsection{Ferric-Reducing Antioxidant Power (FRAP) Assay}

The FRAP assay was performed according to the procedure described by Benzie and Strain [27] with minor modifications. In this assay, $100 \mu \mathrm{L}$ of the diluted sample was added to $3 \mathrm{~mL}$ of the FRAP reagent and the reaction was monitored after $4 \mathrm{~min}$ at $593 \mathrm{~nm}$. The results were expressed as $\mu \mathrm{mol}$ $\mathrm{Fe}(\mathrm{II}) / \mathrm{g}$ fresh weight (FW) of fruit peel.

\subsection{Trolox Equivalent Antioxidant Capacity (TEAC) Assay}

The TEAC assay was performed based on the protocol established previously [28] with minor modifications. Briefly, the $\mathrm{ABTS}^{\bullet+}$ stock solution was prepared from $7 \mathrm{mmol} / \mathrm{L}$ ABTS and $2.45 \mathrm{mmol} / \mathrm{L}$ potassium persulfate in a volume ratio of 1:1, and then incubated in the dark at room temperature for $16 \mathrm{~h}$ and used within two days. A $100 \mu \mathrm{L}$ of the tested sample was mixed with $3.8 \mathrm{~mL} \mathrm{ABTS}^{\bullet+}$ working solution and the absorbance was detected at $734 \mathrm{~nm}$ after incubation at room temperature for $6 \mathrm{~min}$. The percent of inhibition of absorbance at $734 \mathrm{~nm}$ was calculated and the results were expressed as $\mu \mathrm{mol}$ Trolox/g FW of fruit peel.

\subsection{Determination of Total Phenolic Content}

Total phenolic contents were determined with Folin-Ciocalteu method [29]. Briefly, $0.50 \mathrm{~mL}$ extract was mixed with $2.5 \mathrm{~mL}$ of 1:10 diluted Folin-Ciocalteu reagent. After $4 \mathrm{~min}, 2 \mathrm{~mL}$ of saturated sodium carbonate solution was added. The mixture was incubated in dark at room temperature for $2 \mathrm{~h}$ and its absorbance was detected at $760 \mathrm{~nm}$. Gallic acid was used for calibration, and the results were expressed as mg of gallic acid equivalent (mg GAE) per $100 \mathrm{~g}$ FW of fruit peel.

\subsection{Experimental Design}

Optimization of extraction conditions for natural antioxidants from sugar apple peel were carried out using response surface methodology (RSM). A three-variable, five level central composite design (CCD) was applied to determine the best combination of extraction variables. Acetone concentration $\left(X_{1}\right)$, ultrasonic time $\left(X_{2}\right)$, and ultrasonic temperature $\left(X_{3}\right)$ were chosen for independent processing variables. The range and center point values of three independent variables presented in Table 5 were based on the results of preliminary experiments in our laboratory. The CCD in the experimental design consists of twenty factorial points including six replicates of the central point (Table 1), and the experiment was carried out in a standard order. TPC, FRAP, and TEAC were selected as the responses for the combination of the independent variables. All the experiments were performed in quadruplicate, and the average values of the responses were reported. The experimental data from the CCD was analyzed using response surface regression and fitted to a second-order polynomial model (Equation (4)):

$$
Y=\beta_{i}+\Sigma \beta_{i} X_{i}+\Sigma \beta_{i i} X_{i}^{2}+\Sigma \beta_{i j} X_{i} X_{j}
$$

$Y$ is the predicted response, $\beta_{0}$ is an intercept, $\beta_{i}, \beta_{i i}$, and $\beta_{i j}$ are the coefficients of the linear, quadratic, and interaction terms, respectively. $X_{i}$ and $X_{j}$ are coded independent variables.

Table 5. Coded and uncoded levels of the independent variables.

\begin{tabular}{ccccccc}
\hline \multirow{2}{*}{ Independent Variables } & \multirow{2}{*}{ Code Units } & \multicolumn{5}{c}{ Coded Levels } \\
\cline { 3 - 7 } & & $\mathbf{- 1 . 6 8}$ & $\mathbf{- 1}$ & $\mathbf{0}$ & $\mathbf{1}$ & $\mathbf{1 . 6 8}$ \\
\hline Acetone concentration $(\%, v / v)$ & $X_{1}$ & 13.2 & 20 & 30 & 40 & 46.8 \\
Ultrasonic time $(\mathrm{min})$ & $X_{2}$ & 33.2 & 40 & 50 & 60 & 66.8 \\
Ultrasonic temperature $\left({ }^{\circ} \mathrm{C}\right)$ & $X_{3}$ & 43.2 & 50 & 60 & 70 & 76.8 \\
\hline
\end{tabular}


The regression and graphical analysis of the experimental data were performed by Design Expert version 7.1.3 software (Stat-Ease Inc., Minneapolis, MN, USA). The suitability of the model was checked by evaluating the lack of fit, coefficient of determination $\left(R^{2}\right)$, and the Fisher test value ( $F$-value) generated from the analysis of variance (ANOVA) by the software. The difference was considered significant at $p<0.05$.

\subsection{Verification of Model}

The optimum extraction conditions for natural antioxidants depended on acetone concentration, ultrasonic time, and temperature, and were obtained using RSM. For verification of the model, extraction of antioxidants from sugar apple peel was performed under optimal conditions and the extracts were determined. The experimental and predicted values were compared to check the validity of the model.

\section{Conclusions}

An ultrasound-assisted extraction method has been developed for the recovery of natural antioxidants from sugar apple peel. Response surface methodology was used to optimize the experimental variables such as solvent concentration, ultrasonic time, and temperature. The $R^{2}$ values of the second-order polynomial models for TPC, FRAP, and TEAC were 0.9524, 0.9743, and 0.9610, respectively, which indicated a good fit to the quadratic models. The optimal extraction conditions were $20: 1(\mathrm{~mL} / \mathrm{g})$ of solvent-to-solid ratio, $32.68 \%$ acetone and $67.23{ }^{\circ} \mathrm{C}$ for $42.54 \mathrm{~min}$ under ultrasonic irradiation. The application of ultrasound markedly decreased extraction time, and improved the extraction efficiency compared with the conventional methods.

Acknowledgments: This work was supported by the National Natural Science Foundation of China (No. 81372976), Key Project of Guangdong Provincial Science and Technology Program (No. 2014B020205002), and the Hundred-Talents Scheme of Sun Yat-Sen University.

Author Contributions: G.-F.D. and H.-B.L. conceived and designed the experiment. G.-F.D. performed the experiments, analyzed the data, and wrote the paper. H.-B.L., D.-P.X. and S.L. contributed to valuable discussion and revising manuscript.

Conflicts of Interest: The authors declare no conflict of interest.

\section{References}

1. Chumnanpaisont, N.; Niamnuy, C.; Devahastin, S. Mathematical model for continuous and intermittent microwave-assisted extraction of bioactive compound from plant material: Extraction of $\beta$-carotene from carrot peels. Chem. Eng. Sci. 2014, 116, 442-451. [CrossRef]

2. Fernández-Agulló, A.; Freire, M.S.; Antorrena, G.; Pereira, J.A.; González-Álvarez, J. Effect of the extraction technique and operational conditions on the recovery of bioactive compounds from chestnut (Castanea sativa) bur and shell. Sep. Sci. Technol. 2013, 49, 267-277. [CrossRef]

3. Aila, C.M.; Naidu, K.A.; Bhat, S.G.; Prasada Rao, U.J.S. Bioactive compounds and antioxidant potential of mango peel extract. Food Chem. 2007, 105, 982-988.

4. Deng, G.F.; Shen, C.; Xu, X.R.; Kuang, R.D.; Guo, Y.J.; Zeng, L.S.; Gao, L.L.; Lin, X.; Xie, J.F.; Xia, E.Q.; et al . Potential of fruit wastes as natural resources of bioactive compounds. Int. J. Mol. Sci. 2012, 13, 8308-8323. [CrossRef] [PubMed]

5. Kunradi Vieira, F.G.; da Silva Campelo Borges, G.; Copetti, C.; da Valdemiro Gonzaga, L.; Costa Nunes, E.; Fett, R. Activity and contents of polyphenolic antioxidants in the whole fruit, flesh and peel of three apple cultivars. Arch. Latinoam. Nutr. 2009, 59, 101-106. [PubMed]

6. Okonogi, A.; Duangrat, C.; Anuchpreeda, S.; Tachakittirungrod, S.; Chowwana-poonpohn, S. Comparison of antioxidant capacities and cytotoxicities of certain fruit peels. Food Chem. 2007, 103, 839-846. [CrossRef] 
7. Makris, D.P.; Boskou, G.; Andrikopoulos, N.K. Recovery of antioxidant phenolics from white vinification solid by-products employing water/ethanol mixtures. Bioresour. Technol. 2007, 98, 2963-2967. [CrossRef] [PubMed]

8. Kumar, R.; Roopan, S.M.; Prabhakarn, A.; Khanna, V.G.; Chakroborty, S. Agricultural waste Annona squamosa peel extract: Biosynthesis of silver nanoparticles. Spectrochim. Acta A 2012, 90, 173-176. [CrossRef] [PubMed]

9. Srivastava, S.; Lal, V.K.; Pant, K.K. Medicinal potential of Annona squamosa: At a glance. J. Pharm. Res. 2011, 4, 4596-4598.

10. Gan, C.Y.; Latiff, A.A. Optimisation of the solvent extraction of bioactive compounds from Parkia speciosa pod using response surface methodology. Food Chem. 2011, 124, 1277-1283. [CrossRef]

11. Pompeu, D.R.; Silva, E.M.; Rogez, H. Optimization of the solvent extraction of phenolic antioxidants from fruits of Euterpe oleracea using response surface methodology. Bioresour. Technol. 2009, 100, 6076-6082. [CrossRef] [PubMed]

12. Liazid, A.; Barbero, G.F.; Azaroual, L.; Palma, M.; Barroso, C.G. Stability of anthocyanins from red grape skins under pressurized liquid extraction and ultrasound-assisted extraction conditions. Molecules 2014, 19, 21034-21043. [CrossRef] [PubMed]

13. Xia, E.Q.; Ai, X.X.; Zang, S.Y.; Guan, T.T.; Xu, X.R.; Li, H.B. Ultrasound-assisted extraction of phillyrin from Forsythia suspense. Ultrason. Sonochem. 2011, 18, 549-552. [CrossRef] [PubMed]

14. Huang, W.; Xue, A.; Niu, H.; Jia, Z.; Wang, J.W. Optimised ultrasonic-assisted extraction of flavonoids from Folium eucommiae and evaluation of antioxidant activity in multi-test systems in vitro. Food Chem. 2009, 114, 1147-1154. [CrossRef]

15. Chen, Q.H.; Fu, M.L.; Liu, J.; Zhang, H.F.; He, G.Q.; Ruan, H. Optimization of ultrasonic-assisted extraction (UAE) of betulin from white birch bark using response surface methodology. Ultrason. Sonochem. 2009, 16, 599-604. [CrossRef] [PubMed]

16. Wang, L.; Weller, C.L. Recent advances in extraction of nutraceuticals from plants. Trends Food Sci. Technol. 2006, 17, 300-312. [CrossRef]

17. Altemimi, A.; Lightfoot, D.A.; Kinsel, M.; Watson, D.G. Employing response surface methodology for the optimization of ultrasound assisted extraction of lutein and $\beta$-carotene from spinach. Molecules 2015, 20, 6611-6625. [CrossRef] [PubMed]

18. Hossain, M.B.; Rawson, A.; Aguilo-Aguayo, I.; Brunton, N.P.; Rai, D.K. Recovery of steroidal alkaloids from potato peels using pressurized liquid extraction. Molecules 2015, 20, 8560-8573. [CrossRef] [PubMed]

19. Ho, S.K.; Tan, C.P.; Thoo, Y.Y.; Abas, F.; Ho, C.W. Ultrasound-assisted extraction of antioxidants in misai kucing (Orthosiphon stamineus). Molecules 2014, 19, 12640-12659. [CrossRef] [PubMed]

20. Nayak, B.; Dahmoune, F.; Moussi, K.; Remini, H.; Dairi, S.; Aoun, O.; Khodir, M. Comparison of microwave, ultrasound and accelerated-assisted solvent extraction for recovery of polyphenols from Citrus sinensis peels. Food Chem. 2015, 187, 507-516. [CrossRef] [PubMed]

21. Poojary, M.M.; Passamonti, P. Optimization of extraction of high purity all-trans-lycopene from tomato pulp waste. Food Chem. 2015, 188, 84-91. [CrossRef] [PubMed]

22. Karacabey, E.; Mazza, G. Optimization of antioxidant activity of grape cane extracts using response surface methodology. Food Chem. 2010, 119, 343-348. [CrossRef]

23. Haber, A.; Runyon, R. General Statistics, 3rd ed.; Addison-Wesley: Reading, MA, USA, 1977.

24. Joglekar, A.M.; May, A.T. Product excellence through design of experiments. Cereal Food. World 1987, 32, 857-868.

25. Spingno, G.; Tramelli, L.; Faveri, D.M.D. Effects of extraction time, temperature and solvent on concentration and antioxidant activity of grape marc phenolics. J. Sci. Food Agric. 2007, 87, 2817-2822.

26. Re, R.; Pellegrini, N.; Proteggente, A.; Pannala, A.; Yang, M.; Rice-Evans, C. Antioxidant activity applying an improved ABTS radical cation decolorization assay. Free Radic. Biol. Med. 1999, 26, 1231-1237. [CrossRef]

27. Benzie, I.F.F.; Strain, J.J. The ferric reducing ability of plasma (FRAP) as a measure of "antioxidant power": The FRAP assay. Anal. Chem. 1996, 239, 70-76. [CrossRef] [PubMed]

28. Ju, Z.Y.; Howard, L.R. Effects of solvent and temperature on pressurized liquid extraction of anthocyanins and total phenolics from dried red grape skin. J. Agric. Food Chem. 2003, 51, 5207-5213. [CrossRef] [PubMed] 
29. Singleton, V.I.; Rossi, J. Colorimetry of total phenolic with phosphomolybdic-phosphotungstic acid agents. Am. J. Enol. Viticult. 1965, 16, 144-158.

Sample Availability: Not available.

(C) 2015 by the authors; licensee MDPI, Basel, Switzerland. This article is an open access article distributed under the terms and conditions of the Creative Commons by Attribution (CC-BY) license (http://creativecommons.org/licenses/by/4.0/). 